\title{
Fatigue in heart failure outpatients: levels, associated factors, and the impact on quality of life
}

Maria Polikandrioti ${ }^{1}$, Fotios Kalafatakis², Ioannis Koutelekos ${ }^{1}$, Dimitrios Kokoularis ${ }^{3}$

${ }^{1}$ Nursing Department, University of West Attica, Athens, Greece
${ }^{2}$ Undergraduate student, Nursing Department, University of West Attica, Athens, Greece
${ }^{3}$ Biopathology Laboratory, Konstantopouleio Hospital, Athens, Greece

Submitted: 3 February 2019

Accepted: 24 April 2019

Arch Med Sci Atheroscler Dis 2019; 4: e103-e112

DOI: https://doi.org/10.5114/amsad.2019.85406

Copyright (c) 2019 Termedia \& Banach

\section{Abstract}

Introduction: Heart failure (HF) patients experience various psychosocial issues and physical symptoms such as fatigue, which adversely affect their quality of life $(\mathrm{QoL})$. The aim of the study was to assess levels of fatigue in $\mathrm{HF}$ outpatients and the associated factors, as well as to explore the correlation between fatigue and QoL.

Material and methods: One hundred and thirty patients were enrolled in the study. Data collection was performed by the completion of "Minnesota Living With Heart Failure" questionnaire (MLHFQ) and the Greek version of the Modified Fatigue Impact Scale (MFIS-Greek). Data also included self-reported patients' characteristics.

Results: Of the $130 \mathrm{HF}$ outpatients, 50\% scored above 69 (median) in total fatigue and above 41 and 29 (median) in physical and mental fatigue, respectively. Furthermore, 50\% scored above 66 (median) in total QoL and above 32.5 and 13 (median) in the physical and mental state, respectively. These values indicate moderate to high impact of HF on fatigue and on patients' QoL. Total fatigue was statistically significantly associated with NYHA stage $(p=0.001)$, confidence to acknowledge health deteriorations $(p=0.004)$, decrease in appetite $(p=0.001)$, dyspnoea at night $(p=0.001)$, oedema in lower limbs $(p=0.023)$, relation with health professionals $(p=$ $0.031)$, and whether patients had limited daily activities $(p=0.002)$, social contacts $(p=0.014)$, and if they had financial worries $(p=0.003)$. Finally, as the score of fatigue increased, so the QoL score also increased.

Conclusions: A broader understanding of this distressing symptom in HF may contribute to the development of suitable interventions with the ultimate goal of improving QoL.

Key words: heart failure, outpatients, fatigue, quality of life.

\author{
Corresponding author: \\ Maria Polikandrioti \\ Nursing Department \\ University of West Attica \\ 12242 Athens, Greece \\ Phone: +331/6972425054 \\ E-mail: mpolik2006@yahoo. \\ com
}

\section{Introduction}

Heart failure (HF) is a major global health problem associated with increased disability, morbidity, and mortality $[1,2]$. Heart failure incidence is increasing with age, approaching a rate of 10 per 1000 after 65 years of age [3]. Despite recent advances in diagnosis and in therapeutic regimens including new medicines, haemodynamic monitoring, and device therapies, HF incidence remains high mainly due to population aging [2]. However, HF-related issues including prevalence and mortality seem to vary globally. Discrepancies are attributed to different instruments used or to the sample studied and several other disparities [1]. 
This progressive clinical syndrome is characterised by exacerbations leading to frequent hospitalisations or visits to outpatient clinics $[4,5]$. The European Society of Cardiology Heart Failure Long-Term Registry (ESC-HF-LT-R) showed that among 12,440 HF patients in 21 European and Mediterranean countries, $40.5 \%$ were hospitalised with acute HF and $59.5 \%$ were outpatients with chronic HF [4]. In the USA, HF accounts for approximately 3.4 million outpatient visits to physicians, annually [6].

Heart failure is accompanied by several symptoms such as fatigue, shortness of breath, dyspnoea, fluid retention, oedema, and poor exercise tolerance. Fatigue is the most prevalent symptom in $\mathrm{HF}$ patients, ranging from $69 \%$ to $88 \%$ [2] and also in new cases ranging from $10 \%$ to $20 \%$ [7] Approximately $80 \%$ of hospitalised HF patients report experiencing fatigue before hospital admission [8]. The main pathophysiological causes of fatigue are not well understood; however, the predominant factors include impaired peripheral circulatory perfusion with reduced oxygen delivery, autonomic nervous system abnormalities, and impaired muscle strength [7, 9-12].

Notably, this symptom is often unrecognised because its identification depends on self-reporting and is not revealed by physical examination or laboratory and diagnostic tests $[13,14]$. It is not rare that health professionals perceive fatigue as a normal consequence of the disease, which moreover remains untreated due to lack of effective therapeutics. Interestingly, underestimated fatigue is costly to patients' health, thus illustrating the need for early attempts to detect and manage this symptom. Strikingly more, this subjective symptom entails physical and psychological limitations that adversely affect HF patients' quality of life (QoL) [9-12].

Although fatigue is an already known symptom in HF, research is limited. Tang et al. [15] pointed out the following gaps in HF patients: i) there are limited data exploring fatigue; ii) subjective data derived from questionnaires require support from objective data; and iii) studies exploring objective data (such as maximum intake of oxygen, haemoglobin) need to clarify the time between the lab analysis and fatigue evaluation. Furthermore, poor concordance between patients' reports about fatigue and nurses' records is observed [16].

Interestingly, the characteristics of the experience and the consequences of fatigue might be unique to HF patients [11]. It is widely accepted that patients are the best source of subjective information [16]. Exploring HF outpatients' needs, options, and attitudes may be an alternative to confront the increased risk of hospitalisation and early rehospitalisation $[17,18]$.
Hence, understanding patients' self-reported characteristics regarding fatigue is essential to develop suitable therapeutic approaches. At research and clinical levels, assessment of both fatigue and QoL is necessary to evaluate the effectiveness of treatments. The aim of the present study was to: a) assess levels of fatigue and levels of QoL in HF outpatients; b) explore factors associated with fatigue; and c) explore the correlation between QoL and fatigue.

\section{Material and methods}

\section{Participants}

The sample of the study consisted of $130 \mathrm{HF}$ outpatients. In the present study was used the convenience sampling method. The HF patients visited outpatient clinics for routine monitoring and follow-up. These clinics were located in two tertiary university hospitals in Athens. The study lasted from January to October 2018.

During this period, 140 patients were initially identified as eligible to participate in the study, but the present study enrolled only 130 patients because 10 refused to participate.

Criteria for patients' inclusion in the study were as follows: i) age over 18 years; ii) diagnosis of $\mathrm{HF}$ as assessed by a cardiologist and confirmed by medical records; iii) ability to write, read, and understand the Greek language; and iv) the ability to read and sign the informed consent form. The exclusion criteria were as follows: i) patients with a history of mental illness; ii) patients visiting clinics to treat some other co-existing disease and not HF; and iii) patients with cognitive disorders and sight or hearing problems.

The process of filling out the questionnaires lasted between 15 and $30 \mathrm{~min}$ and took place when patients were waiting for their regular follow-up in outpatient clinics.

The present study was cross sectional and there was no intervention group. It merely recorded levels of fatigue and levels of QoL among HF outpatients, the associated factors, as well as the correlation between QoL and fatigue. For this reason, we used the "Minnesota Living With Heart Failure" questionnaire, which is the most widespread instrument to measure QoL in HF, worldwide.

The HF patients are influenced by various factors apart from disease severity, such as socioeconomic background, health awareness about disease, and effective self-management skills. Remarkably, patients' health perceptions have an important impact on the use of health care [16]. Accordingly, the primary focus of the present research was the self-report of patients and not other baseline characteristics such as ejection fraction, heart failure aetiology, number of hospitalisations, ongoing therapy, co morbidities, etc. 


\section{Ethical considerations}

Written, informed consent for participation in this study was obtained from all patients after explanation of the purpose and procedure of the study. Participation in the study was on a voluntary basis, and anonymity was preserved. Furthermore, all participants were informed of their right to refuse or to discontinue their participation, according to the ethical standards of the Helsinki Declaration of 1983. The study was approved by the Medical Research Ethics Committee of the hospital.

\section{Data collection}

Data were collected by completion of the following scales: i) the "Minnesota Living with Heart Failure Questionnaire (MLHFQ)" for the evaluation QoL and ii) the "Modified Fatigue Impact Scale in (MFIS - Greek)" for the evaluation of the fatigue. Data collected for each patient also included demographic and clinical characteristics and other characteristics as self-reported by patients. Demographic variables included gender, age, marital status, educational level, profession, and residency. Clinical variables included NYHA stage, vaccination of flu and pneumococcus, decrease in appetite, dyspnoea at night, and oedema of lower limbs. Other self-reported characteristics included support from family, relation with health professionals, confidence to acknowledge health deterioration, changes in body image, financial worries, and limitations in social contacts and daily activities.

\section{Measuring QoL of HF outpatients}

The "Minnesota Living With Heart Failure" questionnaire (MLHFQ) was used to evaluate QoL [19]. The scale consists of 21 questions that assess patients' QoL in the last month (4 weeks). Respondents are requested to answer every question in a Likert type scale (scores $0-5$ ). The scale consists of two separate groups of questions regarding: i) the physical state and ii) the mental state. The score assigned to the questions is summed separately for questions that assess physical state, for those that assess mental state, and all questions together to an aggregate score, the total QoL. Higher value scores indicate poorer QoL.

\section{Measuring fatigue of HF outpatients}

The Greek version of the Modified Fatigue Impact Scale (MFIS-Greek) was used to evaluate fatigue. This scale was translated into Greek by Bakalidou Dafni in 2014 [20]. The scale consists of 21 questions that assess the fatigue of patients in the last month (4 weeks). Respondents answer every question in a Likert-type scale (scores from 1-5). The scale consists of two separate groups of questions regarding: i) physical fatigue and ii) mental fatigue. The score assigned to the questions is summed separately for questions that assess physical fatigue, for those that assess mental fatigue, and all questions together to an aggregate score, the total fatigue. Higher value scores indicate higher fatigue.

\section{Statistical analysis}

The categorised data are presented in absolute and relevant (\%) frequencies, while the ongoing data present an intermediate and inter-quartile range because they did not follow the common allocation (checked with Kolmogorov-Smirnov and the graphics with Q-Qplots). The non-parametric controls Mann-Whitney and Kruskal-Wallis were used to control the correlation between fatigue and the patients' characteristics. Furthermore, the Spearman's rho control was used to check the correlation between QoL and fatigue. The level of 5\% was considered as statistically significant. All the statistical analysis was made with the $20^{\text {th }}$ version of SPSS (SPSS Inc., Chicago, Il, USA) program.

\section{Results}

\section{Descriptive results}

From the 130 participants, $63.8 \%$ were men, $82.3 \%$ were over 60 years old, $58.5 \%$ were married, and $51.9 \%$ had primary school education. The majority of the sample were pensioners (70.8\%) and residents in Attica (70.5\%) (Table I).

Concerning patients' clinical characteristics, $41.7 \%$ represent NYHA IV, $67.4 \%$ had decreased appetite, $77.8 \%$ had been vaccinated for flu and pneumococcus, $70.5 \%$ had dyspnoea at night, which awaked them, and $77.3 \%$ had oedema in lower limbs (Table II).

In terms of other self-reported characteristics, $61.2 \%$ perceived that their family supports them, $69.8 \%$ has good relations with health professionals, $34.1 \%$ felt very confident to acknowledge deterioration concerning health, $82.9 \%$ reported a change in body image, $82.2 \%$ had limited their daily activities, $37.2 \%$ reported to have "very" limited social contact, and $42.7 \%$ reported experiencing financial worries (Table III).

Table IV presents the results related to fatigue that patients felt. It should be noted that at least $50 \%$ of participants scored 69 (median) in total fatigue, and 41 (median) and 29 (median) in physical and mental fatigue, accordingly.

Furthermore, it is observed that $25 \%$ of the participants scored above 81 in total fatigue, and in terms of physical and mental fatigue, $25 \%$ of participants scored above 47 and above 36, accordingly. 
Table I. Demographic characteristics of HF outpatients $(n=130)$

\begin{tabular}{|c|c|}
\hline Parameter & $N(\%)$ \\
\hline \multicolumn{2}{|l|}{ Gender: } \\
\hline Male & $83(63.8)$ \\
\hline Female & $47(36.2)$ \\
\hline \multicolumn{2}{|l|}{ Age [years]: } \\
\hline$<50$ & $12(9.2)$ \\
\hline $51-60$ & $11(8.5)$ \\
\hline $61-70$ & $18(13.8)$ \\
\hline$>70$ & $89(68.5)$ \\
\hline \multicolumn{2}{|l|}{ Marital status: } \\
\hline Married & $76(58.5)$ \\
\hline Single/separated & $54(41.5)$ \\
\hline \multicolumn{2}{|l|}{ Educational level: } \\
\hline Primary & 67 (51.9) \\
\hline Secondary & $35(27.1)$ \\
\hline Higher & $27(20.9)$ \\
\hline \multicolumn{2}{|l|}{ Occupation: } \\
\hline Unemployed & $6(4.6)$ \\
\hline Private employee & $9(6.9)$ \\
\hline Freelancer & $12(9.2)$ \\
\hline Household & $6(4.6)$ \\
\hline Pensioner & $92(70.8)$ \\
\hline Other & $5(3.8)$ \\
\hline \multicolumn{2}{|l|}{ Residence: } \\
\hline Attica & $91(70.5)$ \\
\hline Other & $38(29.5)$ \\
\hline
\end{tabular}

These values indicate moderate to high effects of HF on patients' fatigue.

Table $\mathrm{V}$ presents results regarding QoL. It is noted that at least $50 \%$ of the patients scored above 66 (median) in total QoL, and scored above 32.5 and above 13 in physical and mental state, respectively. Furthermore, as far as total score is concerned, it is observed that $25 \%$ of the participants scored above 78. In terms of physical and mental state, $25 \%$ of HF patients scored above 36 and above 18 , accordingly.

These values indicate moderate to high effects of HF on QoL.

\section{Factors associated with fatigue}

Table VI presents the factors related to patients' fatigue.
Table II. Patients' clinical characteristics $(n=130)$

\begin{tabular}{|lc|}
\hline Parameter & $\boldsymbol{N}(\%)$ \\
\hline NYHA: & $2(1.6)$ \\
\hline II & $27(21.3)$ \\
\hline IV & $45(35.4)$ \\
\hline Is your appetite decreased? (Yes) & $87(41.7)$ \\
\hline $\begin{array}{l}\text { Have you been vaccinated for flu } \\
\text { and pneumococcus? (Yes) }\end{array}$ & $91(77.8)$ \\
\hline $\begin{array}{l}\text { Dyspnoea at night that awakens } \\
\text { you? (Yes) }\end{array}$ & $91(70.5)$ \\
\hline \begin{tabular}{l} 
Oedema in lower limbs? (Yes) \\
\hline
\end{tabular} & $99(77.3)$ \\
\hline
\end{tabular}

Table III. Patients' self-reported characteristics $(n=130)$

\begin{tabular}{|c|c|}
\hline Parameter & $N(\%)$ \\
\hline \multicolumn{2}{|l|}{$\begin{array}{l}\text { Do you believe that your family } \\
\text { support you? }\end{array}$} \\
\hline Very & $79(61.2)$ \\
\hline Enough & $42(32.6)$ \\
\hline Little & $7(5.4)$ \\
\hline None & $1(0.8)$ \\
\hline \multicolumn{2}{|l|}{ Relation with health professionals: } \\
\hline Very good & $90(69.8)$ \\
\hline Good & $37(28.7)$ \\
\hline Poor & $1(0.8)$ \\
\hline Bad & $1(0.8)$ \\
\hline \multicolumn{2}{|l|}{$\begin{array}{l}\text { How confident do you feel to } \\
\text { acknowledge health deterioration? }\end{array}$} \\
\hline Very & $44(34.1)$ \\
\hline Enough & $48(37.2)$ \\
\hline Little & $26(20.2)$ \\
\hline None & $11(8.5)$ \\
\hline Change in body image? (Yes) & $107(82.9)$ \\
\hline $\begin{array}{l}\text { Do you experience financial worries? } \\
\text { (Yes) }\end{array}$ & $55(42.7)$ \\
\hline $\begin{array}{l}\text { Have you limited your daily activities? } \\
\text { (Yes) }\end{array}$ & $106(82.2)$ \\
\hline \multicolumn{2}{|l|}{ Have you limited your social contacts? } \\
\hline Very & $48(37.2)$ \\
\hline Enough & $52(40.3)$ \\
\hline Little & $14(10.9)$ \\
\hline None & $15(11.6)$ \\
\hline
\end{tabular}


Total fatigue score was statistically significantly associated with NYHA stage $(p=0.001)$, confidence to acknowledge health deteriorations $(p=0.004)$, decrease in appetite $(p=0.001)$, dyspnoea at night $(p=0.001)$, oedema in lower limbs $(p=0.023)$, relation with health professionals $(p=0.031)$, and whether patients had limited daily activities $(p=0.002)$, had limited social contacts $(p=0.014)$, and encountered financial worries $(p=0.003)$. Specifically, higher levels of total fatigue were seen in patients with NYHA IV compared to those with lower NYHA (median: 78 vs. 65 ), those who had little or no confidence to acknowledge health deteriorations (median: 77 vs. 66 and 65 accordingly), those whose appetite was decreased (median: 75), who had oedema ain lower limbs (median: 70.5), who had good relations with health professionals (median: 77), who had limited daily activities (median: 70.5), who had limited social contact (median: 70.5), and those who had financial worries (median: 68).

Physical fatigue was statistically significantly associated with NYHA ( $p=0.001)$, decrease in appetite $(p=0.001)$, dyspnoea at nights $(p=0.001)$, oedema in lower limbs $(p=0.001)$, relations with health professionals $(p=0.032)$, and whether patients had limited daily activities $(p=0.001)$, had limited social contacts $(p=0.003)$, and encountered financial worries $(p=0.001)$. Specifically, higher levels of physical fatigue were seen in patients with NYHA IV, those having a decrease in appetite, dyspnoea at night, oedema in lower limbs, good relations with health professionals, and those who had limited daily activities and social contacts and had financial worries.

Mental fatigue was statistically significantly associated with age $(p=0.003)$, educational level $(p=0.019)$, confidence to acknowledge health deteriorations $(p=0.004)$, decrease in appetite $(p=0.001)$, dyspnoea at night $(p=0.001)$, and whether patients had limited daily activities $(p=$
0.018 ) and social contact ( $p=0.023$ ) or had financial worries $(p=0.031)$. More in detail, patients $>70$ years old experienced higher levels of mental fatigue than those $<70$ years old (median: 30 vs. 20 years) and those with primary education compared to those with secondary and higher education (median: 30.5 vs. 24.5 and 21, accordingly). Also, higher levels of mental fatigue were seen in patients reporting little or no confidence to acknowledge health deterioration, those who had a decrease in appetite, those who had dyspnoea at night, those who had limited daily activities and social contact, and those who had financial worries.

\section{Correlation between fatigue and QoL}

Table VII represents the correlation between fatigue and QoL. Statistically significant positive linear association was observed between fatigue and QoL, which means that as fatigue increases QoL also increases. The more fatigued the patient is, the worse his/her QoL is.

\section{Discussion}

The results of the present study illustrate moderate to high levels of fatigue on HF. According to the literature, levels of fatigue vary from mild to severe based on the sample studied (hospitalised are more symptomatic than stable HF outpatients). Fatigue is a cyclic procedure with unpleasant consequences, which in turn exaggerate this symptom, leading to social isolation [7, 10-12].

The results also revealed that total fatigue was associated with NYHA class, confidence to acknowledge health deterioration, decrease in appetite, dyspnoea at night, oedema in lower limbs, limited daily activities and social contact, and the patient's relationship with health professionals. All these variables associated with fatigue are confirmed by the literature. Relevant studies

Table IV. Measuring fatigue of HF outpatients

\begin{tabular}{|lcc|}
\hline Variable & Average (TA) & Median (IQR) \\
\hline Fatigue total score (sub-scale 21-105) & $68.4 \pm 18.0$ & $69.0(61.0-81.0)$ \\
\hline Physical fatigue (sub-scale 11-55) & $40.7 \pm 10.0$ & $41.0(37.0-47.0)$ \\
\hline Mental fatigue (sub-scale 10-50) & $27.7 \pm 9.7$ & $29.0(21.0-36.0)$ \\
\hline
\end{tabular}

$T A$ - typical aberration, IQR - Inter quartile rate.

Table V. Measuring QoL of HF outpatients

\begin{tabular}{|lcc|}
\hline Variable & Average (TA) & Median (IQR) \\
\hline Total score MINNESOTA (range: 0-105) & $62.6 \pm 20.2$ & $66.0(57.0-78.0)$ \\
\hline Physical state (range: 0-40) & $29.4 \pm 9.8$ & $32.5(27.0-36.0)$ \\
\hline Mental state (range: 0-25) & $12.7 \pm 6.4$ & $13.0(9.0-18.0)$ \\
\hline
\end{tabular}


Table VI. Factors associated with fatigue

\begin{tabular}{|c|c|c|c|c|c|c|}
\hline \multirow[t]{2}{*}{ Parameter } & \multicolumn{2}{|c|}{ Total fatigue } & \multicolumn{2}{|c|}{ Physical fatigue } & \multicolumn{2}{|c|}{ Mental fatigue } \\
\hline & Median (IQR) & $P$-value & Median (IQR) & $P$-value & Median (IQR) & $P$-value \\
\hline Gender: & & 0.822 & & 0.683 & & 0.572 \\
\hline Male & $70(59-81)$ & & $41(37-47)$ & & $28(18-36)$ & \\
\hline Female & $68(61-83)$ & & $42(36-47)$ & & $29(21-34)$ & \\
\hline Age [years]: & & 0.103 & & 0.622 & & 0.003 \\
\hline$\leq 70$ & $64(48-72)$ & & $42(28-50)$ & & $20(17-30)$ & \\
\hline$>70$ & $70(61-82)$ & & $41(37-47)$ & & $30(21-36)$ & \\
\hline Marital status: & & 0.560 & & 0.799 & & 0.727 \\
\hline Married & $71(61-82)$ & & $41(37-47)$ & & $29(21-38)$ & \\
\hline Single/divorced/widowed & $68(61-77)$ & & $41(37-47)$ & & $29(21-32)$ & \\
\hline Education: & & 0.058 & & 0.430 & & 0.019 \\
\hline Primary & $71(65-82)$ & & $41.5(38-47)$ & & $30.5(23-38)$ & \\
\hline Secondary & $66(60-79)$ & & $41.5(37-47)$ & & $24.5(18-30)$ & \\
\hline University & $57(31-78)$ & & $36(19-51)$ & & $21(12-32)$ & \\
\hline NYHA: & & 0.001 & & 0.001 & & 0.057 \\
\hline$|-| I \mid$ & $65(57-77)$ & & $38(34-41)$ & & $28.5(21-32)$ & \\
\hline IV & $78(65-90)$ & & $47(45-50.5)$ & & $34(21-38)$ & \\
\hline $\begin{array}{l}\text { Vaccinated for flu and } \\
\text { pneumococcus: }\end{array}$ & & 0.757 & & 0.085 & & 0.695 \\
\hline No & $69(48-81)$ & & $39(28-45)$ & & $30(20-36)$ & \\
\hline Yes & $69(60-83)$ & & $45(37-48)$ & & $26(21-36)$ & \\
\hline $\begin{array}{l}\text { Acknowledge of health } \\
\text { deteriorations: }\end{array}$ & & 0.004 & & 0.056 & & 0.004 \\
\hline Very & $65(57-75)$ & & $41(36-45)$ & & $21(18-32)$ & \\
\hline Enough & $66(60-83)$ & & $41(37-47)$ & & $28(21-36)$ & \\
\hline A little/not at all & $77(69.5-92)$ & & $46.5(41-51.5)$ & & $32(29-39)$ & \\
\hline Perceived support by family: & & 0.660 & & 0.689 & & 0.307 \\
\hline Very & $68(61-81)$ & & $41(37-48)$ & & $29(21-35)$ & \\
\hline Enough & $68(60-81)$ & & $45(34-47)$ & & $26(17-36)$ & \\
\hline Decreased appetite: & & 0.001 & & 0.001 & & 0.001 \\
\hline No & $65(46-68)$ & & $36(28-45)$ & & $21(16-29)$ & \\
\hline Yes & $75(64-86)$ & & $45(41-48)$ & & $31(23-38)$ & \\
\hline $\begin{array}{l}\text { Dyspnoea at nights that } \\
\text { awakes you: }\end{array}$ & & 0.001 & & 0.001 & & 0.001 \\
\hline No & $65(37-68)$ & & $37(24-45)$ & & $23(13-29)$ & \\
\hline Yes & $75(64-86)$ & & $45(41-48)$ & & $31(21-38)$ & \\
\hline Oedema in lower limbs: & & 0.023 & & 0.001 & & 0.106 \\
\hline No & $66(41-72)$ & & $37(28-44)$ & & $28(13-31)$ & \\
\hline Yes & $70(61-82)$ & & $45(41-48)$ & & $29(21-36)$ & \\
\hline $\begin{array}{l}\text { Relations with health } \\
\text { professionals: }\end{array}$ & & 0.031 & & 0.032 & & 0.086 \\
\hline Very good & $66(59.5-77.5)$ & & $41(36-46)$ & & $27.5(19-32.5)$ & \\
\hline Good & $77(64-86)$ & & $46(41-48)$ & & $31(21-38)$ & \\
\hline Limited daily activities: & & 0.002 & & 0.001 & & 0.018 \\
\hline No & $56.5(30.5-77)$ & & $32(18-45)$ & & $24(12-32)$ & \\
\hline Yes & $70.5(62-83)$ & & $44.5(39-48)$ & & $29(21-36)$ & \\
\hline Limited social activities: & & 0.014 & & 0.003 & & 0.023 \\
\hline
\end{tabular}


Table VI. Cont.

\begin{tabular}{|c|c|c|c|c|c|c|}
\hline \multirow[t]{2}{*}{ Parameter } & \multicolumn{2}{|c|}{ Total fatigue } & \multicolumn{2}{|c|}{ Physical fatigue } & \multicolumn{2}{|c|}{ Mental fatigue } \\
\hline & Median (IQR) & $P$-value & Median (IQR) & $P$-value & Median (IQR) & $P$-value \\
\hline Very & $70.5(64-85)$ & & $43.5(41-49)$ & & $29(21-36)$ & \\
\hline Enough & $68(61-82)$ & & $45(37-48)$ & & $29(21-38)$ & \\
\hline A little/not at all & $61(31-77)$ & & $38(19-45)$ & & $23(12-31)$ & \\
\hline Change in body image: & & 0.572 & & 0.775 & & 0.514 \\
\hline No & $67.5(61-81)$ & & $42(37-48)$ & & $28(21-36)$ & \\
\hline Yes & $71(64-81)$ & & $41(36-47)$ & & $32(21-36)$ & \\
\hline Financial worries: & & 0.003 & & 0.001 & & 0.031 \\
\hline No & $64(48-77)$ & & $41(28-46)$ & & $23.5(17-31)$ & \\
\hline Yes & $68(60-79)$ & & $41(36-45)$ & & $29(21-34)$ & \\
\hline
\end{tabular}

showed that the higher the NYHA class, the higher the level of fatigue, and that depressed patients experience greater fatigue [7, 10-12, 15]. Furthermore, fatigue has a devastating effect on the patient's ability to manage daily activities or adhere to treatment [21, 22]. Additionally, fatigue is associated with mild to moderate anaemia (10-60\%) [7], uncertainty [10], and sleep problems [23].

The finding that $61.2 \%$ of participants declared receiving support from their family is encouraging because support may improve self-management and ultimately improve both fatigue and QoL. Adherence to medical treatment is 1.74 times higher in patients from cohesive families and 1.53 times lower in patients from families in conflict [24]. Family members, especially spouses, are the first to notice new symptoms and generally provide a context of support in several aspects such as dietary and daily weighing [25]. Furthermore, they share the patients' cultural background, thus having appreciation of their deeper needs and perceptions. However, is essential to evaluate quality of support because sometimes family members overstep boundaries, offer unwanted help, or make patients feel less confident [26].

Also worthy of attention is the finding that $69.8 \%$ of participants reported having very good relations with health professionals. HF patients are elderly, usually live alone, have physical or cognitive impairment or several comorbidities, and frequently receive revised self-care instructions after visiting an outpatient clinic. Therefore, building a strong collaborative bond with health professionals might be a key element to improve clinical outcomes and QoL [21].

Perhaps of greater concern is that more fatigue was experienced by participants who did not feel confident to acknowledge health deteriorations. This finding may reflect to some extent the gaps in self-management. The alternative suggestion is that HF symptoms, such as cognitive impairment and fatigue, could hinder patients' ability to acquire knowledge in terms of symptom escalation. Kessing et al. [27] demonstrated that fatigue was associated with poor self-management in $545 \mathrm{HF}$ outpatients (75\% men, average age: 66.2 years). Carlson et al. [28] also showed poor knowledge of the importance of signs and symptoms in $139 \mathrm{HF}$ patients. According to Moser et al. [29], failure to recognise or to respond to worsening symptoms that precede an exacerbation is a common reason for HF preventable readmissions. Patel et al. [30] showed that 50\% of $88 \mathrm{HF}$ patients who sought emergency care had not realised the deterioration of their status, thus delaying seeking treatment. Similarly, Riegel et al. [31] indicated that patients often confuse their HF symptoms for those of other co-morbidities and they rarely link their worsening symptoms to HF. Outpatient HF clinics, which easily provide access to information, counselling, and support should also make efforts to improve symptom interpretation and immediate response in worsening HF.

Patients with primary education experienced mental fatigue. Low education level is associat-

Table VII. Correlation between fatigue and QoL of HF outpatients

\begin{tabular}{|lcccccc|}
\hline Variable & \multicolumn{2}{c}{ MINNESOTA total } & \multicolumn{2}{c}{ Physical state } & \multicolumn{2}{c|}{ Mental state } \\
\cline { 2 - 7 } & $\begin{array}{c}\text { Spearman's } \\
\text { Rho }\end{array}$ & $P$-value & $\begin{array}{c}\text { Spearman's } \\
\text { Rho }\end{array}$ & $P$-value & $\begin{array}{c}\text { Spearman's } \\
\text { Rho }\end{array}$ & $P$-value \\
\hline Total score of fatigue & 0.488 & $<0.001$ & 0.464 & $<0.001$ & 0.416 & $<0.001$ \\
\hline Physical state & 0.559 & $<0.001$ & 0.599 & $<0.001$ & 0.392 & $<0.001$ \\
\hline Mental state & 0.397 & $<0.001$ & 0.338 & $<0.001$ & 0.399 & $<0.001$ \\
\hline
\end{tabular}


ed with failure to understand educational materials, appointment papers or medication labels, and comprehend oral communication provided by health professionals [32]. The complexity of care places this vulnerable group of HF patients at considerable risk for adverse outcomes including high rates of hospitalisation, increased mortality, and worse QoL $[32,33]$. Nurse-delivered interventions, involving structured telephone surveillance, support, and reinforcement of treatment adherence including daily weighing, and salt and fluid restriction might be possible contributors to reducing levels of fatigue among HF patients of low education [34].

In the present study it was also found that participants who encountered financial worries experienced greater fatigue. HF negatively influences financial status due to loss of job or increased medical expenses. Low income is also related to high hospitalisation rates in HF patients [35]

In terms of QoL, results showed moderate to high effects of HF. According to Heo et al. [21], there are three main components in the QoL of HF patients: feeling happy in daily life, having fulfilling relationships with their loved ones, and having the ability to perform physical and social activities. All these dimensions are closely related to symptoms such as fatigue. A relevant study in Greece showed moderate effects of HF on QoL among 300 hospitalised HF patients (90\% aged > 60 years) [36]. Also in the Greek population, Aggelopoulou et al. [37] showed poor QoL in 231 hospitalised HF patients (average MLHFQ score: $65.4 \pm 20.6$ ).

Finally, results revealed that as the patients' fatigue increases, so the OoL decreases. Arueira et al. [38] showed a triad of symptoms that restrict patients' daily life and impact their QoL. This triad includes fatigue, shortness of breath, and bilateral lower-limb oedema and is found in more than $50 \%$ of patients, reaching $80 \%$ in some populations. The same researchers also showed fatigue in $57 \%$ followed by shortness of breath (23\%). They also suggested that poor QoL along with fatigue and shortness of breath (in the absence of other conditions that may be responsible for these symptoms) may have a predictive value for $\mathrm{HF}$ clinical diagnosis.

The ideal proposal is to implement educational programs led by a multidisciplinary team in outpatient clinics, providing for each patient an accurate diagnosis, the appropriate evidence-based therapy and education, as well as symptom monitoring, including fatigue, with the ultimate goal of improving QoL. However, this model is unavailable in most clinical settings and practices $[26,39]$.

Wang et al. [40] applied an educational care program lasting 12 weeks in $92 \mathrm{HF}$ patients who were divided into an intervention group $(n=47)$ and a control group $(n=45)$. In both groups, fatigue and QoL were evaluated at the beginning of the program and after 4, 8, and 12 weeks. Results showed that the intervention group had a decrease in fatigue and an improvement of QoL, whereas no significant changes were observed in the control group. Similarly, an exercise program significantly improves fatigue and QoL from baseline to 12 weeks later [41].

Several limitations of our study must be acknowledged. First, convenience sampling is one of the limitations; this method is not representative of the whole population with HF living in Greece, thus limiting the generalisability of results.

Other limitations are related to the study design, which was cross-sectional and not longitudinal, thus not permitting investigation for a causal relation between fatigue and QoL. Furthermore, there was no other measurement that would display changes in fatigue over time. It would be interesting to know whether persistence of fatigue and changes in fatigue over time are also more important for QoL. Additionally, there was no control group suffering from fatigue without HF. It would be also interesting to explore differences in fatigue and QoL among outpatients and hospitalised patients.

The strengths of the study include the use of a widespread instrument, the "Minnesota Living With Heart Failure" questionnaire, which would allow comparisons among HF populations around the world.

In conclusion, high levels of total fatigue were seen in patients: with NYHA IV, who were poorly or not at all confident to acknowledge health deterioration, who had a decrease in appetite, dyspnoea at night, and oedema in lower limbs, who had good relations with health professionals, who had limited daily activities and social contact, who had financial worries. High levels of physical fatigue were seen in patients: with NYHA IV, with decrease in appetite, dyspnoea at night and lower limb oedema, who had limited daily activities and social contact, who had good relations with health professionals, who had financial worries. High levels of mental fatigue were seen in patients: $>70$ years old, with primary education, who were poorly or not at all confident to acknowledge health deterioration, who had a decrease in appetite and dyspnoea at night, who had limited daily activities and social contact, who had financial worries.

Additionally, the results showed moderate to high effect of HF on fatigue and on QoL. The more fatigue the patients felt, the worse their QoL.

The subjective and multi-dimensional nature of fatigue highlights the need for systematic screening. From a clinical point of view, knowledge about factors associated with fatigue is important when 
identifying high-risk patients who are in need of additional clinical care.

The present findings may guide future interventions and be valuable for both research and clinical practice.

\section{Conflict of interest}

The authors declare no conflict of interest.

\section{References}

1. Savarese G, Lund LH. Global public health burden of heart failure. Card Fail Rev 2017; 3: 7-11.

2. Fini A, de Almeida Lopes Monteiro da Cruz D. Characteristics of fatigue in heart failure patients: a literature review. Rev Latinoam Enfermagem 2017; 17: 557-65.

3. Mirra M, Vitulano G, Virtuoso $\mathrm{N}$, et al. heart failure in a dedicated outpatient clinic: results after 58 month follow-up. Can it be enough? Transl Med UniSa 2014; 11: 59-62.

4. Crespo-Leiro MG, Anker SD, Maggioni AP, et al. Heart Failure Association (HFA) of the European Society of Cardiology (ESC). European Society of Cardiology Heart Failure Long-Term Registry (ESC-HF-LT): 1-year follow-up outcomes and differences across regions. Eur J Heart Fail 2016; 18: 613-25.

5. Chamberlain AM, Dunlay SM, Gerber Y, et al. Burden and timing of hospitalizations in heart failure: a community study. Mayo Clin Proc 2017; 92: 184-92.

6. Wexler R, Elton T, Pleister A, Feldman D. You can do more to slow the progression of heart failure. J Fam Pract 2009; 58: 122-8.

7. Falk K, Swedberg K, Gaston-Johansson F, Ekman I. Fatigue and anemia in patients with chronic heart failure. Eur J Heart Fail 2006; 8: 744-9.

8. Friedman MM, Quinn JR. Heart failure patients' time, symptoms, and actions before a hospital admission. J Cardiovasc Nurs 2008; 23: 506-12.

9. Kurmani S, Squire I. Acute heart failure: definition, classification and epidemiology. Curr Heart Fail Rep 2017; 14: 385-92.

10. Falk K, Swedberg K, Gaston-Johansson F, Ekman I. Fatigue is a prevalent and severe symptom associated with uncertainty and sense of coherence in patients with chronic heart failure. Eur J Cardiovasc Nurs 2007; 6: 99-104.

11. Falk K, Granger BB, Swedberg K, Ekman I. Breaking the vicious circle of fatigue in patients with chronic heart failure. Qual Health Res 2007; 17: 1020-7.

12. Falk K, Patel H, Swedberg K, Ekman I. Fatigue in patients with chronic heart failure - a burden associated with emotional and symptom distress. Eur J Cardiovasc Nurs 2009; 8: 91-6.

13. Polikandrioti M, Tzirogiannis K, Zyga S, et al. Assessment of fatigue in patients with a permanent cardiac pacemaker: prevalence and associated factors. Arch Med Sci Atheroscler Dis 2018; 3: 8-17.

14. Polikandrioti M, Tzirogiannis K, Zyga S, et al. Effect of anxiety and depression on the fatigue of patients with a permanent pacemaker. Arch Med Sci Atheroscler Dis 2018; 3: 166-73.

15. Tang WR, Yu CY, Yeh SJ. Fatigue and its related factors in patients with chronic heart failure. J Clin Nurs 2010; 19: 69-78.

16. Ekman I, Ehrenberg A. Fatigued elderly patients with chronic heart failure: do patient reports and nurse re- cordings correspond? Int I Nurs Terminol Classif 2002; 13: $127-36$

17. Gure TR, McCammon RJ, Cigolle CT, Koelling TM, Blaum CS, Langa KM. Predictors of self-report of heart failure in a population-based survey of older adults. Circ Cardiovasc Qual Outcomes 2012; 5: 396-402.

18. Aronow W. Update of treatment of heart failure with reduction of left ventricular ejection fraction. Arch Med Sci Atheroscler Dis 2016; 1: 106-16.

19. Rector TS, Kubo SH, Cohn JN. Patients' self-assessment of their congestive heart failure. Part 2: content, reliability and validity of a new measure, the Minnesota Living with Heart Failure Questionnaire. Heart Failure 1987; 3: 198-209.

20. Bakalidou D, Voumvourakis K, Tsourti Z, Papageorgiou E, Poulios A, Giannopoulos S. Validity and reliability of the Greek version of the Modified Fatigue Impact Scale in multiple sclerosis patients. Int J Rehabil Res 2014; 37 : 271-6.

21. Heo S, Lennie TA, Okoli C, Moser DK. Quality of life in patients with heart failure: ask the patients. Heart Lung 2008; 38: 100-8.

22. Boyd KJ, Murray SA, Kendall M, et al. Living with advanced heart failure: a prospective, community based study of patients and their carers. Eur I Heart Fail 2004; 6: 585-91.

23. Smith OR, Michielsen HJ, Pelle AJ, Schiffer AA, Winter JB, Denollet J. Symptoms of fatigue in chronic heart failure patients: clinical and psychological predictors. Eur J Heart Fail 2007; 9: 922-7.

24. DiMatteo MR. Social support and patient adherence to medical treatment: a meta-analysis. Health Psychol 2004; 23: 207-18.

25. Sayers SL, Riegel B, Pawlowski S, Coyne JC, Samaha FF. Social support and self-care of patients with heart failure. Ann Behav Med 2008; 35: 70-9.

26. Rosland AM, Piette JD. Emerging models for mobilizing family support for chronic disease management: a structured review. Chronic IIIn 2010; 6: 7-21.

27. Kessing D, Denollet J, Widdershoven J, Kupper N. Fatigue and self-care in patients with chronic heart failure. Eur J Cardiovasc Nurs 2016; 15: 337-44.

28. Carlson B, Riegel B, Moser D. Self-care abilities of patients with heart failure. Heart Lung 2001; 30: 351-9.

29. Moser DK, Frazier SK, Worrall-Carter L, et al. Symptom variability, not severity, predicts rehospitalization and mortality in patients with heart failure. Eur J Cardiovasc Nurs 2010; 10: 124-9.

30. Patel H, Shafazand M, Schaufelberger M, Ekman I. Reasons for seeking acute care in chronic heart failure. Eur J Heart Fail 2007; 9: 702-8.

31. Riegel B, Carlson B. Facilitators and barriers to heart failure self-care. Patient Educ Couns 2002; 46: 287-95.

32. Dennison CR, McEntee ML, Samuel L, et al. Adequate health literacy is associated with higher heart failure knowledge and self-care confidence in hospitalized patients. J Cardiovasc Nurs 2011; 26: 359-67.

33. DeWalt DA, Malone RM, Bryant ME, et al. A heart failure self-management program for patients of all literacy levels: a randomized, controlled trial. BMC Health Serv Res 2006; 6: 30-9.

34. Krumholz HM, Amatruda J, Smith GL, et al. Randomized trial of an education and support intervention to prevent readmissions of patients with heart failure. J Am Coll Cardiol 2002; 39: 83-9.

35. Philbin EF, Dec GW, Jenkins PL, DiSalvo TG. Socioeconomic status as an independent risk factor for hospital readmission for heart failure. Am J Cardiol 2001; 87: 1367-71. 
36. Audi G, Korologou A, Koutelekos I, et al. Factors affecting health related quality of life in hospitalized patients with heart failure. Cardiol Res Pract 2017; 2017: 4690458.

37. Aggelopoulou Z, Fotos NV, Chatziefstratiou Giakoumidakis K, Elefsiniotis I, Brokalaki H. The level of anxiety, depression and quality of life among patients with heart failure in Greece. Appl Nurs Res 2017; 34: 52-6.

38. Arueira HB, Mesquita ET, Kang HC, Miranda VA, Ramos CS, Garcia Rosa ML. Low quality of life as an additional criterion for the clinical diagnosis of heart failure in primary care. Rev Port Cardiol 2012; 31: 559-65.

39. Jaarsma T, Halfens R, Tan F, Abu-Saad HH, Dracup K, Diederiks J. Self-care and quality of life in patients with advanced heart failure: the effect of a supportive educational intervention. Heart Lung 2000; 29: 319-30.

40. Wang TC, Huang JL, Ho WC, Chiou AF. Effects of a supportive educational nursing care programme on fatigue and quality of life in patients with heart failure: a randomised controlled trial. Eur J Cardiovasc Nurs 2016; 15: 157-67.

41. Walsh A, Kitko L, Hupcey J. The experiences of younger individuals living with heart failure. J Cardiovasc Nurs 2018; 33: E9-16. 